International Journal of Instruction e-ISSN: 1308-1470 • www.e-iji.net

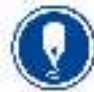

April 2021 • Vol.14, No.2

p-ISSN: 1694-609X

pp. 889-902

Article submission code

20200505142355

Received: 05/05/2020

Revision: 01/11/2020

Accepted: 23/11/2020

OnlineFirst: 12/03/2021

\title{
The Impact of Gender and Degree on The Adult Educator's Theoretical Identity
}

\section{Genovefa Papadima}

University of Macedonia, Greece, gpapadima@uom.edu.gr

This paper aims to highlight a) the adult educator's necessity to take into account the broader philosophical framework that governs his thoughts and practices in the teaching process, $\mathrm{b}$ ) the prevailing educational philosophy or philosophies in active adult educators and c) the gender's and degree's impact on educator's theoretical identity. The research tool is the questionnaire by Lorraine Zinn, "Philosophy of Adult Education" (PAEI) (Zinn, 1983). Both the PAEI and a researcher- created demographic sheet were used to describe and analyze the adult educational philosophies of active adult educators in Greece $(\mathrm{N}=399)$ which guide them and the factors which have impact on these "philosophies". Frequencies, means and correlation analyses were used to describe the results. The research results were shown that the prevailing educational philosophies are the humanism and the progressivism and also that gender and the scientific training of each educator do not appear to influence her/him in terms of the educational philosophy she/he adopts.

Keywords: educational philosophy, adult educator, gender, degree, PAEI

\section{INTRODUCTION}

The importance that modern society attributes to adult education, the breadth of knowledge and skills that is required from adult educators, and the corresponding expectations of learners, lead to the realization that the educator is required to take on a particularly complicated role (Apps, 1973). So, he has to take on a role that responds to these social changes and demands, because he himself is part of that change (Jarvis 1985).

The world is changing very fast thanks to the technological revolution that greatly influences our way of living and the behaviour of both individuals and organizations. Industry 4.0 (also known as Fourth Industrial Revolution) manifests itself in the way data changes, technologies are automated and digitized and it is highly connected with innovation. In the last decade, innovation added further ingredients to the mix - mobile, cloud, social media, and big data also the artificial intelligence and digital physical frameworks make human-machine interface more universal (Morrar, Arman\& Mousa, 2017). This situation has changed the landscape of educational innovation. Adults now

Citation: Papadima, G. (2021). The Impact of Gender and Degree on The Adult Educator's Theoretical Identity. International Journal of Instruction, 14(2), 889-902. https://doi.org/10.29333/iji.2021.14250a 
choose their education approach and define exactly what they need from courses and knowledge rather than passing through the traditional and formal teaching approach, which consider project-based and research-based learning and interactive learning as the top priority.

The education should harness on pertinent information and abilities that couldn't be replaced by robots. Innovation interruption produces Education 4.0 that focuses on educational development and skill has made future learning more customized, hyper, intelligent, portable, worldwide and virtual.

As cutting-edge educators, the adult educators have to investigate new and creative approaches to utilizing educational innovation to upgrade future learning. In this regard, the adult educators have to re-examine their old originations of instructing and learning and upgrade their understudies' learning encounters so they meet the requirements of Education 4.0 (Xu, David, Kim, 2018).

For the aforementioned reason, there is a deep need for adult educator to understand himself as a professional by acknowledging the broader philosophical framework that governs his thinking, choices and practices during the educational process (Papanaoum, 1994). A defined set of values is the most important requirement for the educator, as beneath the individual and institutional practices of adult education underlie a philosophical orientation, whether this is articulated or not (Jarvis, Griffin, 2003). Besides, coupling of educational philosophy and educational practice is necessary given that theory without practice leads to an excessive and sterile idealism, whilst practice without its theoretical underpinnings leads to malign empiricism and unreflective activism (Kumar, 2012).

More specifically, this paper aims to highlight the adult educator's need to take into consideration the broader philosophical framework that governs his thinking, as well as the educational practices, and the way this philosophical background can motivate adult educator to re-evaluate not only himself but, most important, his exertion. According to Apps (1973), the first step in development for adult educator is to identify his educational philosophy. The paper highlights, also, the prevailing educational philosophy of active educators in Greece, as well as the impact of gender and degree on their choices.

\section{REVIEW OF LITERATURE}

Although educational philosophical theories are well theoretically developed, there is no practical connection between them and adult education (Knowles, 1998). Obviously, professional adult educators work without benefiting from the awareness of which educational philosophy they belong. This fact creates issues and shortcomings in a relatively new field of education, a field that could be further developed through a strong theoretical foundation (Merriam\& Brockett, 1997). Consequently, for the professionals in adult education, the sole source of development is their personal experience. Thus, when it comes to decision-making, the scientific examination of 'what it is' has been replaced by a more realistic approach of 'what it works' (Kumar, 2012).

Given that adult educator borne the burden of proper learning process and its coordination is primarily, his multidimensional and demanding role offers relative 
autonomy, but makes any attempt to analyze it difficult (Jarvis, Griffin, 2003). Therefore, the adult educator is called upon to assist the educational process and to carry out any educational activity, having the trainees as recipients and responding to frequently conflicting demands (Reischmann, 2015). This happens because each time he has to deal with a different learner, with different characteristics, needs and expectations, as well as his own way of learning. So, the adult educator ends up being a carrier of a social role which is dependent of his gender and his training in adult education (Papanaoum,1994). Due to the ambiguous field of adult education, both in terms of its objectives and its institutionalization, the adult educator has to understand which educational theory he adopts and therefore he serves (Karavakou\& Papadima, 2015).

Apps (1973) proposes that "why" should precede "what" or "how". This means that before the adult educator decides the content ("what") or the process ("how"), he must primarily research the "why" ("philosophy") that he would like to carry out this program and what are the advantages or disadvantages of its implementation. The question of "why" associated with "Philosophy", which enables the critical understanding of things. Specifically, in the field of adult education, Kumar (2012) states that the answer to the 'why' question offers alternative approaches to curriculum design, to teaching and to evaluation, bearing in mind that values, ethics and Each individual's aesthetics can be enriched. It also highlights the importance of personal trainers' experiences and actions.

Concurrently, the educator is able to develop his own personal philosophy as he is released from all kinds of dependencies, which may come either from his gender or from his dogmatical principles and ideologies.

Consequently, clarifying to what educational philosophical theory belongs, the educator acquires a conscious knowledge of the reasons for which he espouses specific values and assumptions, develops his critical thinking and insight and highlights the timeliness of certain social considerations. In addition, he gains complete control over his educational choices, his teaching design and the distinction between the meaning of this content and the degree of intervention in the syllabus (Brookfield, 1990).

In particular, he acquires a solid basis by being aware of the underlying causes that create his values, assumptions, and choices. In this way, by developing his critical thinking, he is able to distinguish what is valuable to his trainees and to his curriculum (Elias\& Merriam, 1995).

In this area, also it contributes that by discovering his personal educational philosophy the educator facilitates both the way he asks questions and the way he answers the trainees (Bergevin, 1967). At the same time, he becomes better aware of his relationship with his trainees by smoothing out the contradictions and defining their roles. Finally, a key reason for defining his educational philosophy is to clarify the relationship of his work as an adult educator with the problems of society and the individual, by being a self-directed individual (Knowles, 1998• Merriam \& Brockett, 1997).

It should be signalized, however, that the contribution of the educational philosophy, which an adult educator adopts, is never complete as it is constantly evolving and changing, as it is directly dependent on his practical application (Brookfield, 1990). In 
order to answer the question of how educational philosophy contributes, there is a number of other questions, equally important in relation to the purpose of education and learning, the role of the educator and trainee and the impact of his gender or his degree.

\section{Education}

According to Elias \& Merriam (1995) any adult educator is directly influenced by the educational purposes of the program they are about to realize. For example, if the purpose of education is to develop the abilities of the mind (liberalism), the purpose of educators is to educate adults in a broader sense, i.e. mentally, morally and psychologically (Bailey, 2010). Should the purpose be to bring about a behavioral change that will secure the educators' survival within society (behaviorism), their role is to facilitate this change (Higgs\& Smith, 1997). In that case where the purpose of education is to transmit cultural and social changes for the sake of social progress (progressivism), the role of educators is to provide learners with practical knowledge and skills that are necessary for social reform (Jarvis, 2003). If the purpose is (as humanistic theories contend) to render individuals open to change, the role of educators is to reinforce personal development and self realization (Brookfielf, 1986). Last but not least, if the purpose of education is to induce social changes via educational means on social, political and economic issues (radical theory), the role of educators is to change the structure and the political culture of an entire society (Glasersfeld, 1995).

\section{Learning process}

Unlike formal education, in which teachers are responsible for motivating students, the adult learners are actively seeking what educators can offer them, under the condition that what they seek is (or may be) applicable in their actual living situations (Wang, 2003). Also, it is not a surprise that adult learners are a heterogeneous group that transforms the realm of adult education to a very complex one and, in consequence, adult educators are obliged to adopt different kind of responses and methods toward them (Knowles et al, 1998). Educators who embrace radical theory treat adult learners as self-directed individuals with personal motivation (Brooks\& Brooks, 1993). In addition, humanists believe that trainees themselves are responsible for their learning and personal development. Progressivists, also, believe that trainees have unlimited opportunities for personal development through education. In this context the key are learner's needs, interests and experiences (Merriam\& Brockett, 1997). In contrast to the three previous philosophical theories, adult educators, who adopt behaviorism, seek to provide a strong learning environment, which is limited by strict rules. In this environment learners will be able to play an active role in learning, by practicing new behavioral patterns and accepting feedback (Jerling, 1996). Last but not least liberalists argue that adult learners prefer the pure knowledge rather than information (Bailey, 2010).

\section{Educator and learner}

For the adult educator, understanding the complexity of each learner's profile is as important as knowing the subject he is supposed to teach (Wang, 2003). In this context, understanding this heterogeneity and diversity can help adult educators identify which educational philosophy they adopt (Brookfield, 1986, Collins, 1986). If they adopt an 
inappropriate educational philosophy they will undoubtedly fail to serve the needs of adult learners. However, it should be noted that the role of the adult educator varies depending on the philosophical views adopted by both himself and their learners (Karavakou\& Papadima, 2015).

Specifically, adult educators who adopt humanism see themselves as mediators, assistants, and collaborators of learners in the learning process. They even create the right conditions for adult learners, whom they trust, to assume responsibility for what they learn (Elias\& Merriam, 1995). On the contrary, progressivists tend to regard themselves as organizers. They guide the learning process through their own experiences, by motivating learners but also by receiving stimuli from the learners. As a result, their relationships are mutually beneficial, learning from each other (Ellis, 2002). In behaviorism, educators tend to design learning environments that enable them to deliver the intended learning outcomes by causing the desirable behavioral changes (Jerling, 1996). Liberalists consider themselves experts as transmitters of knowledge and they guide clearly the learning process (Jarvis, 2005). Finally, adult educators who adopt radical theory propose but they do not determine learning outcomes by directing the learning process. They are open to both modifications and changes and they practically endorse the equality between educators and learners (Gergen, 1995• Brooks \& Brooks, 1999).

So, it is obvious that the philosophical theory which every adult educator adopts, his "theoretical identity" influences him in the way he approaches his learners, in the roles he adopts and, in the methods, he uses. So, for those who follow liberal philosophy, lectures and critical reading are the preferred approaches to teach adult learners. Intensely programmed teaching (usually with the help of computers) is preferred by behaviorists (Brookfield, 1986). Scientific approaches and problem- solving techniques attract the attention of progressivists, experiential learning is encouraged by humanists and finally, critical dialogue is the main method used by radical educators (Brookfield, 1990).

Thus, the roles of the adult educator are defined as a specialist and knowledge transmitter, as a controller, as a moderator, as a coordinator and mediator and as a contributor to liberal, behavioral, progressive, humanistic and radical philosophical theory (Jarvis, 2006).

\section{METHOD}

\section{Purpose and Objectives}

The purpose of this research was to determine the impact of gender and degree on "theoretical identity" of adult's educators. The objectives were: 1) to determine the prevailing educational philosophy of active adult educators in Greece, 2) to examine the impact of gender and educational level of educators on their educational philosophy.

\section{Limitations of the study}

Participants were selected by random sampling, due to the high cost and time required, but also due to the inability to access the entire sample of the population. The difficulty in accessing the whole sample is big because the competent authorities cannot provide 
personal data collection, as they are considered personal data. Also, another difficulty is that the entire population of trainers is very difficult to find as there is high mobility of trainers and their lack of standing work.

\section{Sample}

The sample of this paper includes adult educators of any specialty who were active during conduction of the research at the Lifelong Learning Centers, affiliated with the Youth and Lifelong Learning Foundation (INEDIVIM). This sample of adult trainers was selected because the educators in a Lifelong Learning Center, they have to qualify for the post. In addition to the higher education degree that must be relevant to their subject matter, they must have and other qualifications related to adult education. These qualifications are a postgraduate or doctoral degree in adult education, his training by public or private providers as well as his teaching experience in adult education (Law No: 3879/2010, Greek Government Gazette No 163/A/ 21-9-2010).

Specifically, the sample size for the survey was 399 adult educators. From the 421 returned questionnaires 399 were retained as 22 were not fully completed. In addition to filling out the PAEI questionnaire, each respondent was required to answer 2 additional demographics, his/her gender and his/her educational level (1st degree, 2nd degree, postgraduate degree, doctoral degree). With regard to gender, it is noted that of the 399 questionnaires, $258(64,8 \%)$ were completed by women and $141(35,2 \%)$ by men. Furthermore, with regard to the highest level of education, 238 questionnaires were completed by educators who have received one bachelor's degree related to their teaching object $(59.6 \%), 42$ by educators of two bachelor's degrees $(10.5 \%), 107$ by holders of a master's degree $(26.8 \%)$ and 12 by doctorate holders (3\%).

\section{Instrument}

To collect the research data, was used, Philosophy of Adult Education Inventory originally developed and documented by Lorraine M. Zinn (1983), which was adapted in Greek. The English questionnaire was translated into Greek (forward translation) separately by two people, without knowing the result between them. This was followed by a comparison of the two translations with the participation of a third person, from which the first version of the questionnaire in Greek (1st reconciliation version) emerged. It was then translated into English (backward translation) by a bilingual person without knowing the original version of the English questionnaire. This is how the second version (2nd reconciliation version) came about, which is the final form given to the respondents.

For its cultural adaptation, the questionnaire was tested to a representative sample of fifteen random individuals with different characteristics. The procedure is the one proposed by the cognitive debriefing process. This questionnaire, which can also serve as a self-evaluating tool, systematizes its questions in categories correlative to the five educational philosophies: the liberalism, the behaviorism, the humanism, the progressivism and the radical theory.

Specifically, the PAEI is a questionnaire with fifteen incomplete sentences, each one resulting in five different choices reflecting the previously mentioned philosophical 
theories. To respond to the inventory question, you have to select the number which most closely represents how you feel about that specific sentence. The scale ranges from strongly disagree with a rating of 1 , to strongly agree with a rating of 7 . At the end of each sentence, after the Likert scale (1-7) there is a right-hand column with ten letters of the English alphabet corresponding to the five educational philosophies. Each educational philosophy represented by two letters, so that the answers cannot be identified and the respondent cannot anticipate the result. These letters are divided into two groups according to their appearance, alternately. More specifically, liberalism corresponds to the sum of the letters: $\mathrm{a}+\mathrm{f}$, behaviorism to the sum: $\mathrm{b}+\mathrm{g}$, progressivism to the sum: $\mathrm{c}+\mathrm{h}$, humanism to the sum: $\mathrm{d}+\mathrm{i}$ and radical theory to the sum: $\mathrm{e}+\mathrm{j}$. The largest sum corresponds to the educational philosophy, which each educator has adopted. In addition, it becomes clear from the beginning that there are no right or wrong answers and the educator chooses the answer that he considers to be closest to what he believes or he does. Zinn remarks that it is also possible to come up with a selfevaluating result according to which, although the educator has an initial philosophical orientation, he may still discover to linger between two different theories. This is the reason for which this questionnaire may be said not to provide us with an absolute selfevaluation result. To this point of view, according to McKenzie (1985) each educational philosophy can exclude another one and there is no educational philosophy that is considered superior or more appropriate than any other. In fact, there are elements of other educational philosophies that are appropriate to an educator with a different philosophical orientation. On this base Rose (2000, p.21) refers to the overlap of educational philosophies on some issues. However, Zinn herself (1991) leaves open the way of exploring possible contradictions in the event of high scores in different educational philosophical theories. Lorraine Zinn herself (1983) tested the questionnaire by in a variety of ways and she concluded that it was reliable and valid. The coefficient Cronbach alpha and one-dimensionality testing, using Principal Component Analysis, were used to assess the reliability and validity of Greek version. For all scales of the questionnaire, the Cronbach's alpha was bigger than $0.80(0.839,0.846,0.844,0.868$, 0.846, 0.813, 0.874, 0.901, 0.888, and 0.886 for scales a, b, c, d, e, f, g, h, i and j, respectively), confirming the reliability. Also, all the scales are characterized by onedimensionality.

\section{Procedures}

The questionnaire's completion was done by self-filling. Prior to the questionnaires being distributed to the trainer population, the required entry permits were secured, following the approval of my request to conduct research in the Program: "Lifelong Learning Centers - National Intervention Programs \& Local Area Programs AP 7 \& AP $8 "$. The questionnaires were sent to the trainers by the Education, Development and Quality Assurance Officers of the different municipalities that belonged.

\section{Statistical Analysis}

A descriptive research survey methodology and a correlational design were used in this study. Data collected were analyzed using SPSS 26. Descriptive statistics such as 
frequencies and means, as well as correlational (Pearson's correlation coefficient) were used to describe and analyze the research data.

\section{FINDINGS}

\section{Philosophy of Adult Education}

A total of 399 questionnaires revealed that 28 trainers were adopting liberalism, 66 behaviorism, 99 progressivism, 149 humanism and 57 radical theory.

As Table 1 shows, of the 258 women, 13 adopt liberalism (5\%), 43 adopt behaviorism (16.7\%), 65 adopt progressivism (25.2\%), 101 adopt humanism (39.1). \%) and 36 are radicals $(14 \%)$. Of the 141 men, 15 identified with the liberal philosophy (10.6\%), 23 identified with behaviorism (16.3\%), 34 identified with progressivism (24.1\%), 48 are humanists (34\%) and 21 are radicals $(14,9 \%)$.

Table 1

Descriptive statistics for gender

\begin{tabular}{lllllll}
\hline & Liberalism & Behaviorism & Progressivism & Humanism & Radical & Total \\
\hline Female & 13 & 43 & 65 & 101 & 36 & 258 \\
\hline Male & 15 & 23 & 34 & 48 & 21 & 141 \\
\hline Total & $28(6,7 \%)$ & $66(16,6 \%)$ & $99(24,9 \%)$ & $149(36,6 \%)$ & $57(15,2)$ & $399(100 \%)$ \\
\hline
\end{tabular}

As can be seen from Table 2, of the 238 holders of one bachelor's degree, 15 adopt liberalism (3.8\%), 44 adopt behaviorism (11\%), 57 adopt the progressivism (14.3\%), 90 adopt humanism (22.6\%) and 32 are radicals (8\%). Of the 42 holders of two bachelor's degrees, 3 are liberalists (0.8\%), 8 are behaviorists (2\%), 11 are progressivists $(2.8 \%)$, 11 are humanists $(2.8 \%)$ and 9 are radicals $(2,3 \%)$. In addition, of the 107 participants, who have received master' $\mathrm{s}$ degree 9 identified with liberal philosophy $(2,3 \%), 13$ identified with behaviorist philosophy (3,3\%), 30 identified with progressivism (7,5\%), 42 respondents are humanists (10,5\%) and 13 are radicals (3,3\%). Lastly, of the 12 doctorate holders only one adopts the liberal philosophy $(0,3 \%)$. The same situation applies to behaviorism and progressivism, too. Only two respondents adopt these philosophies. In contrary, 6 participants adopt humanism (1,5\%) and 3 adopt radical philosophy $(0,8 \%)$.

Table 2

Descriptive statistics for educational level

\begin{tabular}{lllllll}
\hline & Liberalism & Behaviorism & Progressivism & Humanism & Radical & Total \\
\hline $1^{\text {st }}$ degree & 15 & 44 & 57 & 90 & 32 & 238 \\
\hline $2^{\text {nd }}$ degree & 3 & 8 & 11 & 11 & 9 & 42 \\
\hline Master degree & 9 & 13 & 30 & 42 & 13 & 107 \\
\hline Ph.D. & 1 & 1 & 1 & 6 & 3 & 12 \\
\hline
\end{tabular}

Correlation between demographic variables (gender/ degree) and educational philosophies

In order to correlate the gender and educational training of the participants with their personal educational philosophy was used the Chi Square statistic test $\left(\mathrm{x}^{2)}\right.$. More specifically, in order to identify any differences in the distribution of the values of one 
variable with the values of the other Pearson coefficient was used. So, we put to the null hypothesis $\left(\mathrm{H}_{0}\right)$ that the variables "gender" and "educational philosophy" are independent of each other. The test showed that $x^{2}=(4, N=399)=4.816, p=0.307>$ 0.05 .

Therefore, we do not reject the null hypothesis that the gender and educational philosophy adopted by each adult educator are independent of each other. It follows that the gender is not an element that influences the personal educational philosophy.

Subsequently, we compare the variable "scientific training" with the personal educational philosophy of each educator. For this variable there were four options (one bachelor's degree, two bachelor's degrees, master's degree, doctorate degree). It is worth noting that there is a large difference in the number of $\mathrm{PhD}$ holders $\left(\mathrm{N}_{1}=12\right)$ and 2nd bachelor's degree $\left(\mathrm{N}_{2}=42\right)$ compared to master's holders $\left(\mathrm{N}_{3}=108\right)$ and mainly to holders of one bachelor's degree $\left(\mathrm{N}_{4}=240\right)$.

In addition, it should be noted that in the case of this variable "scientific training" it was considered necessary to merge groups due to the proportion that was prohibitive (> $20 \%$ ). Specifically, the educational philosophies were merged into two groups. The first one is student-centered and comprises innovative philosophical theories (radical philosophy, progressivism and humanism) and the second one involves teacher-centered and conservative philosophical theories (liberalism and behaviorism) (Elias\& Merriam, 2005). The categorization is not accidental, but it is based on the main principles of every philosophical theory. However, the association between the scientific training of each respondent and his educational philosophy showed a non-significant difference.

Therefore, as the $\mathrm{x}^{2}$ test shows, using the Pearson coefficient, $\chi^{2}=(3, \mathrm{~N}=399)=1.128$, $\mathrm{p}=0.77>0.05$, the null hypothesis $\left(\mathrm{H}_{0}\right)$ that the scientific training of each adult educator and his educational philosophy are independent variables are not rejected. This fact proves that the scientific training received by each adult educator is not the one that influences him.

\section{DISCUSSION}

From the above results the first finding is that the prevailing educational philosophies are the humanism and the progressivism with a significant precedence, while the liberal philosophy stream is the last with great difference from the others. It is worth noticing that the two "contradictory" educational philosophies, the behaviorism and the radical theory, are almost equal. These differences apply without differentiation, by examining the results under the gender and scientific training of each adult educator. According to the results of inductive statistics gender and the scientific training of each educator do not appear to influence him in terms of the educational philosophy he adopts. As it turned out, these two variables do not affect the adult educator in this choice.

Firstly, gender defines specific patterns of behavior, it imposes expectations, actions and it contributes to the substantiation of gender socialization. It is a determining and selfdetermining factor and these differences accompany the individual during adulthood (Kedraka \& Tsiboulki, 2014, 2017). 
It is logical that expectations and standards of behavior to be expressed during the educational process, especially at the level of goal setting. Men, therefore, under the influence of social norms have internalized certain ways of behaving, which suggest concepts such as autonomy, independence, professional success, prestige, justice, equality, rationality, decision-making, etc. They can operate under a team framework with a distinct hierarchy, which operates to achieve the greatest possible goal in a competitive mood (Morante et al, 2017). On the contrary, women are characterized by more emotional manifestations of their personality. They expect the expression of emotions, companionship, the need for commitment. Men are also motivated by factors of work and social upgrading while women adopt more personal and emotional motivations (Cooley, 2007). One point to be noticed is that men in the educational process show more competitive spirit, claiming superiority. They do not hesitate to engage in verbal confrontations, they seek to show superiority and boost their confidence by securing their dominance, while they show destabilizing tendencies when they lose control and appear weak (Pound, 2017). In contrast, women focus on the emotional capital of education and interpersonal relationships. They seek and encourage with their attitude the development of collaborative practices and work better through the development of collaborative educational practices without the emergence of controversy and verbal disagreements (Pound, 2017).

Regarding the scientific training, it is easy to see that the educational level of the participants in the research is high as they hold Postgraduate and Doctoral degrees. Their motivations are either the acquisition and updating of knowledge or the acquisition of formal qualifications and points. Regarding the first motivation, the acquisition of knowledge, we find that the position of Kokkos et al (2014) is confirmed, which states that the higher the educational level of the people, the more they are interested in acquiring further knowledge. However, in addition to gaining knowledge, the participants had another motivation, which was to obtain points and formal qualifications. Their motivation may be related to the position of Brookfield (2001) who contends that knowledge is commercial and it acquires exchange value as it helps the adult to become more successful in the labor market by overshadowing its true value. So, there is a risk that adult educators will engage in a hunt for skills that can be disastrous and undermine the institution of lifelong learning and its anthropocentric character by making the market captive (Rothes et al., 2017). The question therefore arises neither as to the highest wage or social position, as Brookfield states, nor to the personal advancement and occupation of a higher position in the educational hierarchy but of work itself (Zarifis \&Papadimitriou, 2015).

In fact, it should be borne in mind that the research tool reflects their views at a specific time, in which they may be influenced by various factors (from their trainees, from the teaching subject etc.). This fact does not make the result fixed. The trainers themselves may be record different results at a different time and under other conditions. After all, this is a self-assessment questionnaire and educators can easily find it and complete it again (Zinn, 1983). 


\section{CONCLUSION}

At this point comes the notion of emancipation through theory and practice which Freire (1985) advocated. Therefore, this approach requires trainers to explore and understand the ideological basis of their practices, because theory and practice are interrelated. According to Kossivaki (2003), theory constitutes practice. She remarks (Kossivaki, 2003) that teaching effectiveness depends on: a) the skills and policies that educator has acquired empirically in his professional life and $b$ ) his theoretical knowledge. For this reason, at the present research attempted to reflect not only the prevailing educational philosophy of adult educators who work in non-formal education structures but also it reflects whether or not their views are influenced by their gender and their scientific training.

However, it is not important for an adult educator to adopt a particular educational philosophy that someone oblige him to do. In contrary, the important thing is that his teaching practice is based on a valid educational theory that he has consciously or unconsciously chosen (Papastamatis, 2010).

Utilizing these theoretical bases, the adult educator is able to review not only his behavior towards his trainees but also the teaching practices he used in the past. So, he begins to dispute his own personal positions for his personal development as an individual. It is obvious, then, that adult education, like any other level of education, must be based on theoretical thought. In conclusion, theory and practice are part of a unique reality and cannot be separated (Karavakou\& Papadima, 2015). McKenzie's phrase (1985, p.12) illustrates the necessity of coexistence between theory and practice. He supports that both theorist and the professional should combine theory and practice and not limit themselves. Such a practice would turn the former into a "rigid" scientist and the latter a professional without a theoretical background.

Finally, it is worth noticing that defining educational philosophy is a necessary but not sufficient condition for solving problems, which the adult educator faces. In addition, political and institutional support as well as the cultivation of a wider culture are clearly needed for adult education (Radovan, 2012). In the future there will be a lot of changes in ways of teaching and learning. The content of the teaching, roles of lecturers and students. The logic of education systems should be reversed so that it is the system that conforms to the learner rather than the learner to the system. This is the essence of personalization and this is a consequensce of Fourth Industrial Revolution. Digital skills and the way they can be used in adult education will bring benefits to the individual, society and the economy. In particular, they contribute to personal development, improve opportunities for vocational rehabilitation, the competitiveness of the national economy, reduce social inequality and increase social cohesion, inclusion and active citizenship (Sivathanu\& Pillai, 2018). Regarding their development, emphasis should be placed on the design of appropriate educational programs, which will be authentic and "problem-centric", ie focused on the work tasks and problems of adults. Equally important is securing financial incentives and funding mechanisms. Also, of major importance is the support of actions and investments in infrastructure, devices, platforms and hardware (Shahroom\& Hussin, 2018). 
Nevertheless, the awareness of the educational philosophy makes the adult educator capable of responding to the challenges of his duties. This paper can be the stimulus for the institutionalization of adult educator' $\mathrm{s}$ "theoretical identity", looking at his work not as a total but as individual units of a total.

\section{REFERENCES}

Apps, J. W. (1973). Toward a working philosophy of adult education. Syracuse, NY: Syracuse University.

Bailey, C. (2010). Beyond the Present and the Particular: A Theory of Liberal Education. London: Routledge and Kegan Paul.

Bergevin, P. (1967). A philosophy for adult education. New York: The Seabury Press.

Brookfield, S. D. (1986). Understanding and facilitating adult learning. San Francisco: Jossey-Bass.

Brookfield, S. D. (1990). The skillful teacher: On technique, trust, and responsiveness in the classroom. San Francisco: Jossey-Bass.

Brookfield, S.D. (2001). Repositioning ideology critique in a critical theory of adult learning. Adult Education Quarterly, 52(1), 7-22.

Brooks, J. \& Brooks, M. (1993). In search of understanding: The case for constructivist classrooms. Alexandria, VA: Association for Supervision and Curriculum Development.

Collins, M. (1986). Philosophy and the role of the adult educator. Paper presented at the Annual Meeting of the American Association for Adult and Continuing Education. Hollywood, FL. (ERIC Reproduction Service No. ED277859).

Cooley, L.A. (2007). Transformational learning and third-wave feminism as potential outcomes of participation in women's enclaves. Journal of Transformative Education, 5(4), 304-316.

Elias, J. L., \& Merriam, S. B. (1995). Philosophical foundations of adult education, $\left(2^{\text {nd }}\right.$ ed.), Malabar, FL: Krieger Publishing Company.

Ellis, M. L. (2002). Using the Pragmatic Progressive Philosophy in Adult Education. $U$. S. Department of Education, 1-11.

Freire, P. (1985). The Politics of Education: Culture, power and liberation. South Hadley, MA: Bergin and Garvin.

Gergen, K.J. (1995). The Social Constructivist Movement in Modern Psychology. American Psychologist, 40, 266-75.

Higgs, P. \& Smith, J. (1997). Workbook for theoretical frameworks in Education. Study Guide 1 for ETH201N. Pretoria: University of South Africa.

Jarvis, P. (1985). The Sociology of Adult and Continuing Education. London \& New York: Routledge. 
Jarvis P. (2003). Adult Education and Lifelong Learning: Theory and Practice. ( $3^{\text {rd }}$ ed). London \& New York: Routledge.

Jarvis, P. (2005). International Dictionary of Adult and Continuing Education. London: Taylor\& Francis e-Library.

Jarvis P. (2006). Education and Training of Teachers and Trainers: A European Policy Framework, in Kapsalis, A.\& Papastamatis, A., Professionalism in Continuing Education. Athens: Dardanos, 65- 80.

Jarvis, P., Griffin, C. (2003). Adult and Continuing Education: Major Themes in Education. London: Routledge.

Jerling, K. (1996). Onderwys, opleiding en ontwikkeling in organisasies. Pretoria: Kagiso.

Karavakou, V. \& Papadima, G. (2015). Why do adult educators need to know their personal educational philosophy?, in Digital Proceedings from $3^{\text {rd }}$ International Symposium on New Issues on Teacher Education- ISNITE 2015, Volos: University of Thessaly Press.

Kedraka, K., \& Tsiboukli, A. (2014). Male and Female Adult Educators: Critical rethinking on differences and similarities. Workshop in the Proceedings of the Conference: "Interrogating transformative processes in learning and education: an international dialogue", (pp.391-396). European Society for Research on the Education of Adults (ESREA) Network, 27-29/06/2013, Athens, Greece.

Kedraka, K., \& Tsiboukli, A. (2017). Transformative Experiences of Female Adult Educators in Greek Academia: Gender Free or Not?, Multilingual Academic Journal of Education and Social Sciences, 5(1), 39-49.

Knowles, M. (1998). The adult learner: A neglected species (5th ed.). Houston, TX: Gulf Publishing Company.

Kossivaki, F. (2003). Alternative Didactics: Suggestions for Transitioning from the Teaching of the Subject to the Teaching of the Active Subject. Athens: Gutenberg. [in Greek]

Kumar, Ajay (2012). Philosophical Background of Adult and Lifelong Learning. $\begin{array}{llll}\text { Retrieved } & 15 & \text { November, } & 2016\end{array}$ http://www.unesco.org/education/aladin/paladin/pdf/unit03.pdf

McKenzie, L. (1985). Philosophical orientation of adult educators. Lifelong Learning 9(1), 18-20. (ERIC Document Reproduction Service No. EJ 320 691).

Merriam, S.B.\& Brockett, R.G. (1997). The Profession and Practice of Adult Education. San Francisco: Jossey- Bass.

Morante, A. et. al. (2017). Gender differences in online participation: examining a History and a Mathematics Open Foundation online course. Australian Journal of Adult Learning, 57(2), 266-293. 
Morrar, R., Arman, H. Mousa, S. (2017). The Fourth Industrial Revolution (Industry 4.0): A Social Innovation Perspective, Technology Innovation Management Review, 7(11), 12-19.

Papanaoum Z. (1994), Adult educators: issues o professionalization, in Benn R. \& Fieldhouse R. (eds), Training and professional development in Adult and Continuing Education. University of Exeter, Centre for Research in Continuing Education.

Papastamatis, A. (2010). Adult Education: Foundations of Teaching Practice. Athens: Sideris. [in Greek]

Pound, P. (2017). What is best practice in sex and relationship education? A synthesis of evidence, including stakeholders' views. BMJ Open, doi: 10.1136/bmjopen-2016014791.

Reischmann, J. (2015). Professionalization of adult education: Some aspects. Andragogical Studies, 2, 23-37

Radovan, M. (2012). Understanding the Educational Barriers in Terms of the Bounded Agency Model. Journal of Contemporary Educational Studies, 90-107.

Rose, A. D. (2000). Philosophy is not a diagnosis. Adult Learning, 11(2), 20-22.

Rothes, A., Lemos, M. S., \& Gonçalves, T. (2017). Motivational profiles of adult learners. Adult Education Quarterly, 67(1), 3-29.

Shahroom, A.A., Hussin, N. (2018). Industrial Revolution 4.0 and Education, International Journal of Academic Research in Business and Social Sciences, 8(9), 314319.

Sivathanu, B., Pillai, R. (2018). Smart HR 4.0 - how industry 4.0 is disrupting HR, Human Resource Management International Digest, https://doi.org/10.1108/HRMID04-2018-0059.

Von Glasersfeld, E. (1995). A constructivist approach to teaching, in Steffe, L. \& Gale, J. (Eds), Constructivism in Education. New Jersey: Lawrence Erlbaum Associates, Inc., 3-16.

Wang, V., (2003). Principles of adult education. Boston: Pearson Custom Publishing.

Xu, M. David, J.M. Kim, S.H. (2018), The Fourth Industrial Revolution: Opportunities and challenges, International Journal of Financial Research, 9(2), 90-95.

Zarifis, Georgios K. \& Papadimitriou, Achilleas (2015). What Does it Take to Develop Professional Adult Educators in Europe? Some Proposed Framework Guidelines. Andragoške Studije, 2, 9-22.

Zinn, L. M. (1983). Development of a valid and reliable instrument to identify a personal philosophy of adult education. Doctoral dissertation. Florida: Florida State University.

Zinn, L., (1991). Identifying Your Philosophical Orientation. In Knowles, M. Adult Learning Methods. Malabar, Florida: Krieger Publishing Company, 39-78. 